\title{
Participación del Negro en la Independencia de la Nueva Granada y Venezuela. (1810-1830)
}

\section{Eduardo Perez Ochoa}

La proyección histórica de a esclavitud en su forma colonial y ritmo mercantil, aportó a América el negro y con él la segunda fuerza social y política que intervendría en la consecución del Estado Nacional o en el mantenimiento del Régimen Colonial.

Al lado de la rebeldía indígena, la del elemento de color constituye el verdadero transfondo de la movilización rural para el momento de la independencia.

De ésta rebeldía podría señalarse una compleja estadística, de la cual para Iberoamérica daremos muestras regionales. Igual cosa puede decirse para el medio Neogranadino y Venezolano, pues aquí como en el resto del continente, desde que pisaron tierra Americana los negros lucharon por su libertad, ya de manera individual, de grupo o de comunidad cimarrona o palenquera, algunas veces en confabulación con los indios.

Al interior del conflicto de independencia la insurrección negra, había creado en las montañas zonas de autodefensa donde obraban comó un "contra-Estado" al orden establecido.

La actividad bélica negra puede tener sus diferencias temporales según al marco económico que enfoquemos, pero también suscitar graduales analogías, por ejemplo en la modalidad de guerra empleada, cuyas acciones siempre estaban encaminadas a "conseguir armas y municiones, liberar esclavos de las minas, haciendas y en los ingenios, ajusticiar amos y administradores o simplesmente llevar el terror al enemigo". 
Ganar la fuerza negra para la continuidad colonial o para las conquistas demo-liberales fué preocupación de las élites blancas contrapuestas y así al sentido político que tomó esa masa, determinó el triunfo de la fase restauradora y luego el de la fase republicana. Pero aristomonárquicos como aristorepublicanos se cuidaron siempre del temor a desembocar con el odio de casta, en una revolución de corte social.

Durante el período de la "Patria Boba" la comunidad negra permaneció en igual o en peores condiciones que antes, sin haber obtenido reivindicaciones significativas continuaron insurreccionandose ahora contra sus nuevos amos y la nueva clase dominante, la de los criollos. La rebeldía negra hace en especial "La guerra del monte" con la cual toma minas y reparten tierras. A esa guerra los republicanos no podrán vencer solamente con el poder de sus armas y ejército, sino que han de necesitar de medidas más profundas de caracter social y político.

Los conductores de la revolución de independencia o de la contrarevolución, jugaron con el elemento de manumisión, según las necesidades de la guerra progresivamente irían graduando las medidas libertarias. El derecho a la propiedad y aún la participación política de los sectores populares en la estructura del poder.

Del lado venezolano plantadores y ganaderos inicialmente se habían opuesto a las reformas coloniales, como las de "cedulas de gracias al sacar", de la misma manera se opusieron a admitir en las milicias a negros, pardos y mulatos. Este y otros precedentes sumados a la táctica política proespañolista, como la de Boves de aparentar ser reformadores sociales, daría al traste con la primer República.

En el sector Neogranadino se destacan dos núcleos de resistencia al cambio: uno al norte en el litoral Atlántico y otro al sur-oeste en la región patiano-pastusa. En ambos casos existió heterogeneidad de movimientos así por ejemplo en la independencia de Cartagena fué importante la movilización de las masas urbanas de negros y mulatos, y en el sur José Hilario Mora y algunos aventureros ingleses comandando negros asaltaban haciendas de los españoles; igualmente se intentó en el litoral Pacífico insurreccionar en las minas de 3.000 a 4.000 negros.

En cambio en la sub-región patiana sus habitantes, quienes eran una mezcla de negros libertos con nativos de ese medio, no habían permitido la entrada a las autoridades coloniales, ni tampoco permitió la de los 
criollo-republicanos; pero en el fragor de la primera campaña del sur, los guerrilleros negros o mulatos como el grupo de Juan J. Caizedo, al inclinarse por la causa colonial definieron la caída de la llamada "Patria Boba".

En la segunda fase de la independencia y a partir de 1815-16, los criollos debido a su experiencia anterior se preocuparon por ser capaces de elaborar para el negro un proyecto político social, que fuera alternativa al presentado por los españoles. Bolívar mismo manumitió sus esclavos y en Margarita proclamó: "No habrá pues más esclavos en Venezuela que los que quieran serlo, todos los que prefieran la libertad al reposo tomarán las armas para sostener sus derechos sagrado y ser ciudadanos" y más adelante escribía "he proclamado la libertad absoluta de los esclavos".

Esa actitud, no era más que el correctivo a la postura inicial del precursor Miranda condicionando la libertad del negro a 10 años de servicio en las fuerzas republicanas y a la indemnización a sus dueños. Igual cosa que a las disposiciones de 1813, señaladas por José Felix de Restrepo sobre manumisión o "libertad de vientres".

De otra parte, fue a Páez a quien correspondió ganar las fuerzas populares diseminadas en la Guayana y en los llanos, entre estas las situadas en el Alto Orinoco, dirigidas por el comandante "El negro Rojas". Para este objetivo Páez a más de la libertad ampliada, imitó los señuelos que había utilizado Boves esto es, la participación en el botín de guerra, repartos de tierra y haberes de los españoles. Mientras esto sucedía en la llanura Neogranadina y antes de la llegada de Santander y Bolivar, el mulato Nonato Pérez con similares tácticas y utilizando el método de guerrillas había consolidado la independencia de Casanare.

En el área montañosa del interior existe similar heterogeneidad política con los movimientos de los negros y de otras categorias sociales, pero los españoles a veces pudieron, en su provecho, hacer funcionar la institución esclavista con proclamas como esta: "Los esclavos que aseguren o presenten un cabecilla o jefe revolucionario a quien pertenezca se les concederá la libertad una gratificación pecuniaria y además seran condecorados conforme al mérito". Negros asaltan haciendas y caminos de los actuales Santanderes y Antioquia, en esta última al tomarse un cuartel cae prisionero entre otros Antonio Villavicencio. 
El sur por largos años continuó refractario a la causa demo-liberal, solo hasta el año 22 sería franquedo el valle del Patía, no sin antes los rebeldes de este medio ayudados de su especial topografía, asestar considerables golpes a las fuerzas regulares de los criollos.

Sucre prefirió por vía marítima esquivar el paso de ese tapón físico y humano, corredor de seguridad realista apoyado en sectores de negros, mulatos e indios; el mismo Bolívar también lo hubiera preferido si no es porque frente a Buenaventura se encontraba vigilante la escuadra española. Ante la realidad de tener que cruzar por "esas termópilas", pensó en algo que pareciera inaudito como era el armisticio, pues se iba a jugar más de 10 años de lucha acumulada y por ello escribió: "voy a dar un combate más aventurado que el de Boyacá y lo voy a dar con rabia y con desprecio, con el ánimo de triunfar o de no volver". Se enfrentaría no solo al poderío militar español refugiado allí, sino a la alianza de indios y de negros acaudillados por el nativo Agustín Agualongo y por el guerrillero negro, Toro.

Las condiciones para el triunfo en el área también fueron más políticas que militares, Bolívar así se lo había propuesto al indemnizar con dinero los recursos gastados o debastados, y sobre todo al ganar la fuerza y simpatía de algunos jefes de bandas y cuadrillas o de personalidades de influencia regional como Obando. De esta forma surgieron divisiones en los patianos, un grupo se mantendría pro-colonialista, otro pro-republicano y un tercero indistintamente atacaría a las propiedades y al ejército de los españoles y de los criollos. Con esta política si se quiere se impidió o se fustró la segunda y esperanzada reconquista.

Fué en el sur donde el Libertador frente a las reflexiones comunicadas por Santander de lo peligroso y antieconómico que resultaban para los criollos las disposiciones ampliadas de libertad, Bolívar contestó: "Me parece una locura que en una revolución de libertad se pueda mantener la esclavitud".

En el período Grancolombiano fuerzas negras asediaron varias veces la ciudad de Popayán, mientras en el litoral Pacífico de Buenaventura a Iscuandé, estas fuerzas son utilizadas por gamonales y caciques políticos para pretender hacer de diccha región una república independiente. En el litoral Atlántico son notables las insurrecciones de negros en especial en la región de Lorica. En la zona de Maracaibo a 
Coro, en un solo año 44 hay levantamientos. En las montañas y valles de los alrededores de Caracas el indio Cisneros apoyado también por negros mantendría de las postreras, la más tenaz de las resistencias procolonialistas. En Cumaná y Barcelona, indios y negros mezclados, atacaron y saquearon las ciudades y el campo.

En Angostura la fracasada toma del cuartel dirigida por "facciosos" de los negros, hará que éstos sean ajusticiados en la plaza pública. Sucedía todo esto con "negros alzados" contra la nueva estructura de poder, estructura que fué incapaz de solucionar el hambre y la crisis económica de la post guerra y la que además se había mostrado indiferente a la constante violación de las leyes de manumisión, por el contrario había creado la institución policiva la cual tenía entre sus objetivos el de reprimir las subversiones de los negros, se presentaran estas con conciencia de raza, de grupo o de clase o fueran producto de un proceso de descomposición al bandidaje clásico. 